\title{
HUBUNGAN ANTARA EFIKASI DIRI AKADEMIK DENGAN PENYESUAIAN DIRI PADA MAHASISWA BARU PROVINSI NTT YANG MERANTAU DI UNIVERSITAS KRISTEN SATYA WACANA SALATIGA
}

\author{
Toar Shamgar Mamesah ${ }^{1}$, Ratriana Y.E Kusumiati ${ }^{2}$ \\ Email:mamesahtoar@gmail.com ${ }^{1}$ \\ Fakultas Psikologi, Universitas Kristen Satya Wacana ${ }^{1,2}$
}

\begin{abstract}
Abstrak
Penelitian ini berujuan untuk mengetahui hubungan antara efikasi diri akademik dengan penyesuaian diri pada mahasiswa baru provinsi NTT yang merantau di UKSW Salatiga Responden dalam penelitian ini berjumlah 51 orang.Variabel efikasi diri akademik diukur dengan menggunakan Academic Self-Efficacy Scale yang dirancang khusus oleh Muhammed Ashraf. Variabel penyesuaian diri diukur dengan skala yang dikembangkan dari teori Schneider (1964).. Koefisien korelasi yang diperoleh sebesar 0.564 dengan nilai signifikansi $0,000(\mathrm{p}<0,05)$. Kesimpulan dari penelitian ini adalah adanya hubungan yang positif antara efikasi diri akademik dengan penyesuaian diri pada mahasiswa baru provinsi NTT yang merantau di Universitas Kristen satya wacana Salatiga.

Kata Kunci :Efikasi Diri Akademik; Penyesuaian Diri; Mahasiswa Baru
\end{abstract}

\begin{abstract}
This study aims to determine the relationship between academic self-efficacy and adaptation to new NTT province students who migrate to SWCU Salatiga Respondents in this study amounted to 51 people. Academic self-efficacy variables were measured using the Academic Self-Efficacy Scale specifically designed by Muhammed Ashraf. The self-adjustment variable is measured by a scale developed from Schneider (1964). The correlation coefficient obtained is 0.564 with a significance value of 0.000 ( $p<0.05$ ). The conclusion of this study is that there is a positive relationship between academic self-efficacy and adjustment to the new NTT Province students who migrate to Satya Wacana Christian University in Salatiga.

Key Words :Academic Self-efficacy; Adjustment; New students
\end{abstract}

\section{Pendahuluan}

Pada umumnya, Setiap mahasiswa baru mengalami masa transisi dari sekolah menengah atas menuju perguruan tinggi. Disini mereka akan menghadapi suasana lingkungan baru, misalnya mendapatkan struktur sekolah yang lebih besar dan tidak bersifat pribadi, interaksi dengan kelompok sebaya dari daerah yang lebih beragam dan terkadang dengan latar belakang etnik yang lebih beragam lagi, dan peningkatan perhatian atas prestasi akademik dan penilainya (Santrock, 2002). Pascarella dan
Terenzini (1991) mendeskripsikan masa transisi sebagai sebuah "culture shock" yang melibatkan pembelajaran kembali terhadap masalah sosial dan psikologis dalam menghadapi hal baru, pengajar dan` teman baru dengan nilai dan berbagai keyakinan, kebebasan dan peluang baru, dan tuntutan akademik, personal, dan social yang baru (Pascarella \& Terenzini, 1991).

Fenomena merantau menurut Kato (2005) adalah sebagian individu yang meninggalkan kampung halaman untuk mencari kekayaan ilmu, pengetahuan, 
dan kemakmuran.Bentuk migrasi ini tidak permanen dan pada umumnya perantau memiliki hubungan yang kuat dengan kampung halamannya.Merantau telah menjadi budaya hidup banyak orang di Indonesia khusunya bagi mahasiswa baru yang ingin mencari pendidikan yang lebih baik dari tempat asalnya.Banyak alasan yang mendasari para pelajar untuk melanjutkan studi ke perguruan tinggi di Pulau Jawa.Merantau dalam rangka mendapat pendidikan yang lebih tinggi merupakan salah satu alasan para remaja yang baru saja lulus SMA yang ingin melanjutkan kuliah ke daerah diluar daerah asalnya, misalnya ke Pulau Jawa. Tidak hanya berasal dari Pulau Jawa tetapi juga berasal dari luar Pulau Jawa, seperti Sumatera, Kalimantan dan Sulawesi, dan daerah-daerah Indonesia Timur.

Melalui proses dalam masa transisi sebagai mahasiswa baru, adanya tantangan yang harus dihadapi. Menurut Arkoff (1968) penyesuaian diri terhadap perguruan tinggi merefleksikan bagaimana pencapaian seorang dalam melewati berbagai tuntutan di dalam perguruan tinggi dan bagaimana berdampak pada perkembangan diri. Dengan kata lain, bagaimana mereka menyesuaikan diri juga bergantung pada kemampuan dalam mencapai kelulusan (Arkoff, 1968). Baker dan Siryj (1984) menyebutkan bahwa penyesuaian diri terhadap perguruan tinggi merupakan kesejahteraan seorang mahasiswa yang berhubungan dalam hal akademik, sosial, stabilitas emosi, dan komitmen terhadap institusi atau perguruan tinggi (Baker \& Siryk, 1984).

Kegagalan remaja dalam melakukan penyesuaian diri akan menimbulkan bahaya seperti tidak bertanggung jawab dan mengabaikan pelajaran, sikap sangat agresif dan sangat yakin pada diri sendiri, perasaan tidak aman, merasa ingin pulang jika berada jauh dari lingkungan yang tidak dikenal, dan perasaan menyerah. Bahaya yang lain adalah terlalu banyak berkhayal untuk mengimbangi ketidakpuasannya, mundur ke tingkat perilaku yang sebelumnya, dan menggunakan mekanisme pertahanan seperti rasionalisasi, proyeksi, berkhayal, dan pemindahan (Hurlock, 1997).

Penyesuaian diri diperlukan remaja dalam menjalani transisi kehidupan, salah satunya adalah transisi peralihan pendidikan.Transisi peralihan pendidikan adalah perpindahan siswa dari jenjang pendidikan yang rendah ke jenjang pendidikan yang lebih tinggi 
tingkatannya.Pada dasarnya transisi tersebut adalah pengalaman normatif bagi semua mahasiswa, tetapi hal tersebut dapat menimbulkan stres.

\section{KAJIAN PUSTAKA}

Schneiders (1964) menyebutkan bahwa ada beberapa faktor yang mempengaruhi penyesuaian diri, diantaranya mampu mengontrol emosionalitas yang berlebihan, mampu mengatasi mekanisme psikologis, mampu mengatasi perasaan frustasi pribadi, kemampuan untuk belajar, kemampuan memanfaatkan pengalaman, memiliki sikap yang realistis dan objektif. Salah satu faktor tersebut mempengaruhi penyesuaian diri yaitu Kondisi Psikologis.Kondisi psikologis meliputi keadaan mental individu yang sehat.Individu yang memiliki mental yang sehat mampu melakukan pengaturan terhadap dirinya sendiri dalam perilakunya secara efektif. Menurut Bandura (dalam Smet, 1994) untuk mengatur perilaku akan dibentuk atau tidak, individu tidak hanya mempertimbangkan informasi dan keyakinan tentang keuntungan dan kerugian, tetapi juga mempertimbangkan sampai sejauh mana individu mampu mengatur perilaku tersebut. Kemampuan ini disebut dengan keyakinan diri.
Keyakinan diri adalah perasaan individu akan kemampuannya mengerjakan suatu tugas. Keyakinan diri mengacu pada persepsi tentang kemampuan individu untuk mengorganisasi dan mengimplementasi tindakan pada yang dibutuhkan untuk menampilkan kecakapan tertentu (Bandura, 1986).Keyakinan diri akademik disebut juga sebagai efikasi diri akademik. Baron dan Byrne (2004) membagi efikasi diri kedalam tiga jenis yaitu efikasi diri sosial, efikasi pengaturan diri, dan efikasi diri akademik.

Efikasi diri akademik yang didefinisikan oleh Baron dan Byrne (2004) adalah keyakinan individu terhadap kemampuannya untuk mengerjakan tugas, untuk mengatur aktivitas belajarnya sendiri, untuk mewujudkan harapan akademik baik harapan akademik dari diri sendiri maupun dari orang lain. Efikasi diri akademik diartikan sebagai keyakinan mahasiswa terhadap kemampuannya untuk melaksanakan dan mengorganisasikan suatu kegiatan tertentu dengan baik.

Mahasiswa yang memiliki efikasi diri akademik yang baik akan lebih mungkin untuk terlibat dalam kegiatan 
akademik dan merasa yakin bahwa individu mampu sukses menjalaninya. Selain itu individu juga akan berani dalam menetapkan target pencapaian yang tinggi. Efikasi diri akademik pada mahasiswa akan mempengaruhi pemilihan aktivitas, tujuan, dan usaha serta persistensi individu dalam aktivitasaktivitas kelas (Schunk \& Pajares, 2001).

Rendahnya efikasi diri akademik juga dapat menyebabkan individu putus sekolah.Berdasarkan penelitian yang dilakukan oleh Peguero dan Shaffer (2014), efikasi diri akademik dapat memfasilitasi kemajuan pendidikan dan meminimalkan risiko putus sekolah pada remaja.

Efikasi diri akademik dapat memfasilitasi kemajuan pendidikan serta meminimalkan risiko putus sekolah pada remaja.Mahasiswa yang memiliki efikasi diri yang baik juga dapat dibuktikan dengan prestasi akademiknya.Hal ini dapat diukur melalui Indeks Prestasi (IP) maupun Indeks Prestasi Kumulatif (IPK) serta ketepatan waktu dalam menyelesaikan pendidikan.Dengan demikian, dapat dikatakan bahwa prestasi akademik merupakan indikator dari penguasaan bahan kuliah yang telah dicapai mahasiswa, dan nilai (IP/IPK) dapat dijadikan tolok ukur hasil pembelajaran terakhir dari penguasaan berbagai mata kuliah tersebut di perguruan tinggi.

Sesuai dengan fenomena yang ada di Universitas Kristen Satya Wacana Salatiga yang mahasiswanya berasal dari berbagai macam latar belakang kehidupan dan budaya.Hal tersebut juga terikat pada mahasiswa baru di Universitas Kristen satya wacana khususnya mahasiswa yang merantau harus dapat beradaptasi dengan baik dengan lingkungan barunya.

Banyak mahasiswa baru yang merantau merasa mudah beradaptasi dengan lingkungan di perguruan tinggi yang biasa disebut dengan "Indonesia Mini” dan ada juga mahasiswa merantau yang kesulitan untuk beradaptasi dengan lingkungan perguruan tinggi. Mahasiswa baru yang merantau dan memiliki keyakinan diri yang rendah mengalami kesusahan dalam menyesuaikan diri dengan lingkungan baru, baik dalam bahasa maupun kesulitan untuk menyesuaikan diri dengan lingkungan dan cuaca di kota yang ditempatinya.

Berdasarkan hasil wawancara yang telah dilakukan pada 3 mahasiwa baru provinsi NTT yang merantau, dan mendapatkan hasil bahwa mahasiswa seringkali menghadapi tekanan ketika dia 
menginjakkan kaki di lingkungan perguruan tinggi yang memang sangat berbeda dengan lingkungan mereka semasa di SMA. Mulai dari proses pembelajaran, teman sebaya yang memang berasal dari berbagai macam pulau, hubungan mahasiwa dengan dosen, serta peraturan yang mereka dapatkan di kampus membuat mereka kesulitan dalam menyesuaikan diri.

Berdasarkan beberapa penelitian sebelumnya yang dilakukan Mahendrani \& Rahayu (2014) mengatakan bahwa ada hubungan yang positif antara efikasi diridengan penyesuaian diri.Lebih lanjut penelitian yang dilakukan Irfan \& Suprapti (2014) juga mengatakan bahwa efikasi diridan penyesuaian diri mempunyai hubungan yang positif dimana ketika efikasi diri yang tinggi maka penyesuaian dirinya juga tinggi begitu juga sebaliknya.Hee-Sook Sim \& Weon-Hee Moon (2015) dalam penelitiannya juga mengatakan bahwa terjadi hubungan yang positif antara efikasi diridan penyesuaian diri.

\section{METODE PENELITIAN}

Jenis penelitian yang digunakan adalah penelitian kuantitatif dengan desain korelasional.Variabel bebas dalam penelitian ini adalah efikasi diri akademik, sedangkan variabel terikat adalah penyesuaian diri. Definisi operasioan setiap varibel dijelaskan sebagai berikut :

\section{Penyesuaian Diri}

Schneiders (1964) mendefenisikan penyesuaian diri sebagai suatu kemampuan untuk berinteraksi secara efektif dan bermanfaat terhadap realitas, situasi dan relasi sosial sehingga kriteria yang harus dipenuhi dalam kehidupan sosialnya dapat terpenuhi dengan caracara yang dapat diterima dan memuaskan.Variabel penyesuaian diri diukur berdasarkan aspek-aspek yang dikemukakan Schneiders (1964) (a) Kontrol terhadap emosi yang berlebihan, (b) Mekanisme pertahanan diri yang minimal, (c) Frustrasi personal yang minimal, (d) Pertimbangan rasional dan kemampuan mengarahkan diri, (e) Kemampuan untuk belajar dan memanfaatkan pengalaman masa lalu, (f) Sikap realistik dan objektif

\section{Efikasi diri akademik}

Bandura (1995) mengemukakan bahwa efikasi diri akademik adalah penilaian diri sendiri atas suatu kemampuan untuk mengatur dan melaksanakan kegiatan belajar untuk mencapai hasil prestasi berdasarkan tingkatan yang ditunjukan.Variabel efikasi diri akademik diukur dengan skala 
yang mengacu pada Abdul \& P.Ashraf (2006) yaitu academic self-efficacy scale dengan menerapkan aspek-aspek dari teori efikasi diri dari Bandura (1995) yaitu (a) level, (b) generality, (c) strength Partisipan dalam penelitian ini adalah mahasiswa baru angkatan 2017-2018 yang merantau yang berjumlah 51 orang yang terdaftar sebagai mahasiswa UKSW di Salatiga.Teknik pengambilan sempel dalam penelitian ini menggunakan teknik sampling jenuh, yaitu teknik pengambilan sampel dengan mengambil semua populasi untuk menjadi sampel. Partisipan diambil sesuai denga kriteria yang sudah ditentukan sebelumnya yaitu : (a) mahasiswa /mahasiswi aktif Universitas Kristen Satya Wacana, (b) mahasiswa/mahasiswi angkatan 20172018 yang berasal dari provinsi NTT, (c) berusia 18-20 tahun.

Alat ukur dalam penelitian ini menggunakan dua skala yaitu, skala penyesuaian diri dan skala efikasi diri akademik. Alat ukur yang digunakan untuk mengukur efikasi diri akademik adalah diukur dengan skala yang mengacu pada Abdul \& P.Ashraf (2006) yaitu academic self-efficacy scale dengan menerapkan aspek-aspek dari teori efikasi diri dari Bandura (1995) kemudian diadaptasi oleh peneliti ke dalam bahasa Indonesia dan disesuaikan dengan kepentingan penelitian. Alat ukur yang digunakan untuk mengukur penyesuaian diri adalah skala yang dibuat oleh peneliti berdasarkan aspek-aspek yang dikemukakan Schneiders (1964) yang dikaitkan dengan penyesuaian diri di dalam kampus.

Skala efikasi diri akademik memiliki 37 item pernyataan dengan empat pilihan jawaban yaitu, Sangat Tidak Setuju (STS), Tidak Setuju (TS), Setuju (S), Sangat Setuju (SS). setelah dilakukan diskriminasi item melalui corrected item-total correlation diperoleh 7 item yang memiliki koefisien korelasi $\leq$ 0,25 dan dinyatakan gugur. Berdasarkan hasil uji realibilitas, diketahui bahwa aitem efikasi diri akademik dari 37 aitem menjadi 30 aitem dengan memiliki dengan tingkat Cronbach's alpha sebesar 0,717 sehingga skala psikologi dalam variabel efikasi diri akademik dinyatakan reliable.

Skala penyesuaian diri Skala ini memiliki 19 item pernyataan dengan empat pilihan jawaban yaitu, Sangat Tidak Setuju (STS), Tidak Setuju (TS), Setuju (S), Sangat Setuju (SS). Setelah dilakukan diskriminasi item melalui corrected item-total correlation diperoleh 9 item yang memiliki koefisien korelasi $\leq$ 
0,25 dan dinyatakan gugur sebanyak 9 aitem. Berdasarkan hasil uji reliabiltas, diketahui bahwa aitem penyesuaian diri dari 19 aitem menjadi 10 aitem dengan koefisian Cronbach's alpa sebesar 0.774 sehingga skala psikologi dalam varibel penyesuaian diri dinyatakan reliabel. Metode analisis data yang digunakan adalah teknik correlation product moment dari Karl Pearson, dengan bantuan program statistic SPSS versi 18.0 for windows.

\section{HASIL PENELITIAN}

Hasil analisis deskriptif terhadap variabel efikasi diri akademik dan penyesuaian diri diperoleh hasil sebagai berikut: (a) sebesar $60.78 \%$ subyek memiliki efikasi diri akademik dengan kategori sedang, (b) sebesar 62,78\% subyek memiliki penyesuian diri dengan kategori sedang . hasil tersebut dapat dilihat pada tabel di bawah ini :

Tabel 1. Analisa Deksriptif Penyesuaian diri

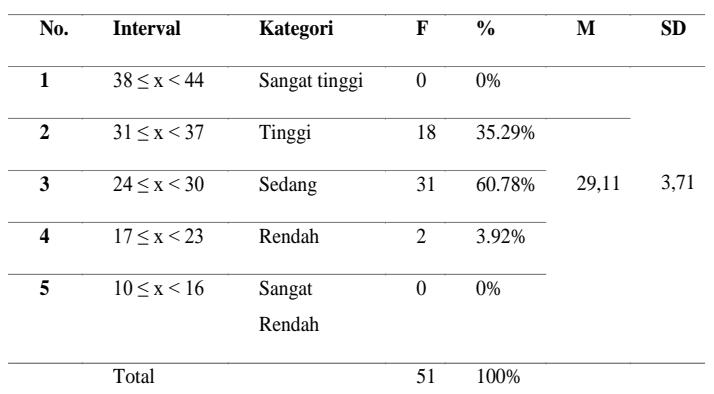

Tabel 2 Analisa Deskriptif Efikasi Diri Akademik

\begin{tabular}{lllllll}
\hline No. & Interval & Kategori & F & $\%$ & M & SD \\
\hline $\mathbf{1}$ & $106 \leq \mathrm{x}<124$ & Sangat tinggi & 1 & $1.96 \%$ & 83,3 & 8,99 \\
\hline $\mathbf{2}$ & $87 \leq \mathrm{x}<105$ & Tinggi & 18 & $35.29 \%$ & & \\
\hline $\mathbf{3}$ & $68 \leq \mathrm{x}<86$ & Sedang & 32 & $62.78 \%$ & & \\
\hline $\mathbf{4}$ & $49 \leq \mathrm{x}<67$ & Rendah & 0 & $0 \%$ & & \\
\hline $\mathbf{5}$ & $30 \leq \mathrm{x}<48$ & Sangat Rendah & 0 & $0 \%$ & & \\
& & & & & & \\
\hline & Total & & 51 & $100 \%$ & &
\end{tabular}

Penelitian ini menggunakan uji normalitas yang bertujuan untuk mengetahui normal atau tidaknya distribusi data penelitian masing-masing variabel dan menggunakan uji linearitas.Dari hasil uji normaliats sampel berdistribusi normal, pada variabel penyesuian diri diperoleh K-S-Z 0.668, nilai sig 0.763 , pada variabel efikasi diri akademik diperoleh $\mathrm{K}-\mathrm{S}-\mathrm{Z}$ 0.693, nilai sig 0.723.hasil uji linearitas menunjukan adanya hubungan yang linear antar efikasi diri akademik dengan penyesuaian diri dengan deviation form linearity $\mathrm{F}$ beda $=1.369 \mathrm{p}=0.106$.

\section{Tabel 3 Uji Normalitas}

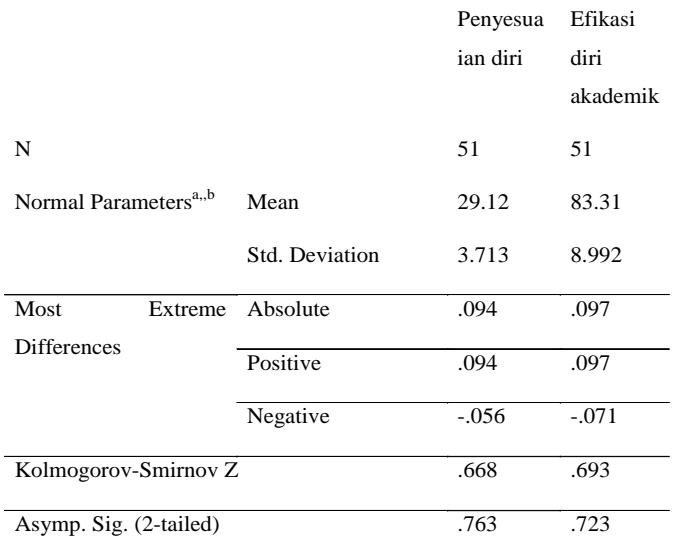


Dari hasil uji asumsi menunjukan bahwa data yang diperoleh berdistribusi normal dan variabel-variabel penelitian linear, maka dalam penelitian ini menggunakan uji korelasi statistic parametik. Uji korelasi yang digunakan dalam penelitian ini adalah korealsi product moment pearson.

Hasil uji korealsi menunjukan bahwa ada hubungan positif signifikan antara efikasi diri akademik dengan penyesuaian diri dengan $r=0.564$ dengan nilai signifikan $0,000(\mathrm{p}<0,05)$ yang dapat diartikan hipotesis dalam penelitian ini diterima. Semakin tinggi efikasi diri akademik mahasiswa maka semakin tinggi penyesuaian diri mereka terhadap lingkungan yang dihadapi.Begitu juga sebaliknya, semakin rendah efikasi diri akademik yang dimiliki maka semakin rendah tinkat penyesuaian diri mereka terhadap lingkungan baru. Seperti yang ada pada tabel di bawah ini :

Tabel 4.Uji Korelasi Efikasi Diri Akademik dan Penyesuaian Diri

\begin{tabular}{lll|ll} 
& & $\begin{array}{l}\text { Penyesu } \\
\text { aian diri }\end{array}$ & $\begin{array}{l}\text { Efikasi } \\
\text { akademik }\end{array}$ & Diri \\
\hline Penyesuaian diri & $\begin{array}{l}\text { Pearson } \\
\text { Correlation }\end{array}$ & 1 & $.564^{* *}$ \\
\cline { 2 - 4 } & Sig. (1-tailed) & & .000 \\
\cline { 2 - 4 } & $\mathrm{N}$ & 51 & 51 \\
\hline $\begin{array}{l}\text { Self-efficacy } \\
\text { akademik }\end{array}$ & Pearson & $.564^{* * *}$ & 1 \\
& Correlation & & \\
\cline { 2 - 4 } & Sig. (1-tailed) & .000 & \\
\cline { 2 - 4 } & $\mathrm{N}$ & 51 & 51
\end{tabular}

\section{PEMBAHASAN}

Berdasarkan penelitian mengenai hubungan efikasi diri akademik dengan penyesuaian diri pada mahasiswa baru provinsi NTT yang merantau di UKSW Salatiga didapatkan hasil adanya korelasi positif yang signifikan antara efikasi diri akademik dengan penyesuaian diri ( $\mathrm{r}=$ 0.564), hal ini menunjukkan bahwa semakin tinggi efikasi diri akademik pada mahasiswa baru provinsi NTT yang merantau di UKSW, maka semakin tinggi penyesuaian diri yang muncul. Seperti beberapa penelitian sebelumnya yang dilakukan Mahendrani \& Rahayu (2014) mengatakan bahwa ada hubungan yang positif antara efikasi diri dengan penyesuaian diri.Lebih lanjut penelitian yang dilakukan Irfan \& Suprapti (2014) juga mengatakan bahwa efikasi diri dan penyesuaian diri mempunyai hubungan yang positif dimana ketika efikasi diri yang tinggi maka penyesuaian dirinya juga tinggi begitu juga sebaliknya.HeeSook Sim \& Weon-Hee Moon (2015) dalam penelitiannya juga mengatakan bahwa terjadi hubungan yang positif antara efikasi diri dan penyesuaian diri.

Mahasiswa yang memiliki efikasi diri akademik yang baik cenderung akanmemiliki penyesuaian diri yang baik. Hal ini dapat terlihat dengan bagaimana 
individu mampu menjalani tugas akademik dan cara beradaptasi dengan orang lain,lingkungan dan masalah yang dihadapi. Hal ini juga disebabkan oleh keyakinan individu yang yang cukup tinggi terhadap kemampuan yang dimilikinya sehingga individu dapat melakukan dan menyelesaikan kewajiban sebagai mahasiswa.Menurut Schunk \& Pajares (2001) bahwa Efikasi diri akademik pada mahasiswa dapat mempengaruhi pemilihan aktivitas, tujuan, dan usaha serta persistensi individu dalam aktivitas-aktivitas kelas.Namun sebaliknya, jikaefikasi diri akademik yang dimiliki individu rendah hal ini dapat menyebabkan hal-hal negatif yang akan muncul seperti putus sekolah, kurang bertanggung jawab, jiwa sosial yang rendah.

Dilihat dari mahasiswa yang memiliki tipe efikasi diri akademik dengan ketegori kategori sedang memiliki presentasi sebesar $60.78 \%$, tinggi memiliki presentase sebesar $35.29 \%$, kategori rendah dengan presentase $3.92 \%$. Sedangkan tipe penyesuaian diri memiliki kategori presentase 62,78\%, kategori tinggi memiliki presentase $35.29 \%$, sangat tinggi dengan presentase $1.96 \%$. Dalam hal ini, tinggi rendahnya penyesuian diri pada mahasiswa, bisa dilihat melalu efikasi diri akademik mereka. Efikasi diri akademik pada mahasiswa akan mempengaruhi pemilihan aktivitas, tujuan, dan usaha serta persistensi individu dalam aktivitas-aktivitas kelas (Schunk \& Pajares, 2001).

Berdasarkan hasil uji korelasi, adapun sumbangan efektif yang diberikan efikasi diri akademik terhadap penyesuaian dirisebesar $31,8 \%$. Hal ini mengindikasikan bahwa masih ada $68,2 \%$ faktor-faktor luar yang mempengaruhi, seperti yang dikatakan Schneiders (1964) bahwa ada beberapa faktor yang mempengaruhi penyesuaian diri, diantaranya mampu mengontrol emosionalitas yang berlebihan, mampu mengatasi mekanisme psikologis, mampu mengatasi perasaan frustasi pribadi, kemampuan untuk belajar, kemampuan memanfaatkan pengalaman, memiliki sikap yang realistis dan objektif.Penyesuaian diri dengan lingkungan akademik dipengaruhi oleh seberapa besar kesanggupan dan keyakinan dirinya untuk mengerjakan tugas dan peran barunya sebagai seorang pelajar di sekolah atau disebut sebagai efikasi diri akademik.

Berdasarkan hasil analisa deskriptif dalam penelitian ini, Dilihat dari 
mahasiswa yang memiliki tipe efikasi diri akademik dengan ketegori kategori sedang memiliki presentasi sebesar $60.78 \%$, tinggi memiliki presentase sebesar 35.29\%, kategori rendah dengan presentase $3.92 \%$. Sedangkan tipe penyesuaian diri memiliki kategori presentase 62,78\%, kategori tinggi memiliki presentase $35.29 \%$, sangat tinggi dengan presentase $1.96 \%$. dari hasil perhitungan di atas, rata-rata yang didapat dari efikasi diri akademik pada mahasiswa termasuk dalam kategori 'sedang', sedangkan untuk penyesuaian diri termasuk dalam kategori 'sedang'.

Berdasarkan penjelasan diatas, dapat disimpulkan bahwa efikasi diri akademik merupakan salah satu faktor yang bisa mempengaruhi penyesuaian diri pada mahasiswa baru provinsi NTT yang merantau di UKSW. Berdasarkan hal tersebut dapat disimpulkan bahwa mahasiswa baru provinsi NTT yang merantau yang memliki efikasi diri akademik yang sedang, ia akan selalu mencoba melakukan berbagai tugas dan tindakan serta menghadapu kesulitankesulitan yang ada. Hal ini diasumsikan bagi setiap mahasiswa dan mahasiswa yang dalam setiap pembelajaran yang ada mereka mampu untuk bersaing dalam proses belajar. Sehingga efikasi diri akademik pada mahasiswa baru provinsi NTT yang merantau sangat menentukan seberapa besar usaha yang dikeluarkan dan seberapa mampu ia bertahan dalam lingkungan yang memberikan suasana yang berbeda dengan tempat tinggal aslinya. Semakin kuat efikasi diri akademik pada mahasiswa maka semakin giat dan tekun dalam usaha-usaha yang diberikan.

Ketika menghadapi kesulitan, mahasiswa yang mempunyai keraguan besar tentan kemampuanya akan mengurangi usaha-usahanya bahkan dapat menyerah sama sekali. Sedangkan mereka yagn mempunyai efikasi diri akademik yang kuat menggunakan yang lebih besar untuk menghadapi tantangan atau masalah yang muncul.

\section{KESIMPULAN}

Dari hasil penelitian dan pembahasan yang telah ditunjukkan di atas, maka kesimpulan yang didapat oleh peneliti adalah sebagai berikut (a) Adanya hubungan positif signifikan antara efikasi diri akademik dengan penyesuaian diri pada mahasiswa baru provinsi NTT yang merantau di UKSW Salatiga. Maka, semakin tinggi efikasi diri akademik mahasiswa maka semakin tinggi penyesuaian diri.Sebaliknya, semakin rendah efikasi diri maka 
semakin rendah penyesuaian diri mereka. (b)Berdasarkan hasil uji korelasi, adapun sumbangan efektif yang diberikan efikasi diri akademik terhadap penyesuaian diri sebesar $31,8 \%$. Hal ini mengindikasikan bahwa masih ada $68,2 \%$ faktor-faktor luar yang mempengaruhi. (c) Efikasi diri akademik termasuk dalam kategori sedang,yaitu60.78\%, sama halnya dengan penyesuaian diri juga termasuk dalam kategori sedang,yaitu 62,78\%

Berdasarkan hasil penelitian dan kesimpulan di atas, maka peneliti menyarankan kepada mahasiswa, lembaga pendidikan dan peneliti selanjutnya, (a) Mahasiswa/mahasiswi diharapkan untuk meningkatkan keyakinan diri mereka terhadap kemampuan yang dimiliki, agar dapat memiliki penyesuaian diri yang baik dengan lingkungan atau orang-orang di sekitar, dan mahasiswa/mahasiswa diharapkan untuk tidak mudah putus asa sehingga dapat terhindar dari hal-hal yang negatif dan lebih memilih untuk terus berusaha untuk menyelesaikan halhal yang menjadi kewajiban mereka. (b) Lembaga pendidikan perlu memberikan motivasi yang positif melalui dosen/pengajar sehingga membuat mahasiswa mendapat dukungan atas keyakinan mereka terhadap kemampuan yang dimiliki, dan juga sekolah perlu memfasilitasi banyak kegiatan-kegiatan positif agar mahasiswa dapat berkembang secara kognitif dan sosial, sehingga mereka dapat belajar beradaptasi yang baik dengan lingkungan dan orang-orang sekitanya. (c) Bagi peneliti selanjutnya diharapkan dapat mempertimbangkan faktor-faktor lain yang berpengaruh terhadap penyesuaian diri, seperti dukungan sosial, pengaruh teman dekat atau orang lain dan dapat melakukan penelitian pada tingkat pendidikan lain dengan ciri khas yang berbeda atau beragam.

\section{DAFTAR PUSTAKA}

Alisjahbana, Sidharta, M., Brouwer, M.A.W. 1983.Menuju Kesejahteraan Jiwa. Jakarta : PT.Gramedia.

Atwater, E. 1979.Psychology of Adjustment 2nd Edition. New Jersey : PrenticeHall Inc.

Baron, R. A., \& Donn, B. 2003.Psikologi Sosial. Jakarta: Erlangga.

Bandura, Albert. 1995. Self efficacy : In Changing Societies. United Kingdom: Cambridge University Press

Brown, N. 2008.Predicting College Adjustment: The Contribution of Generation Status and Parental Attachment.Albany State University of NewYork.

Calhoun, J.F dan Acocella, J.R. 1990.Psikologi tentang Penyesuaian dan Hubungan Kemanusiaan.(Terjemahan oleh 
Satmoko).Semarang

:IKIP

Semarang Press.

Fitri, R., \& Kustanti, E. R. 2018. Hubungan Antara Efikasi Diri Akademik Dengan Penyesuaian Diri Akademik Pada Mahasiswa Rantau Dari Indonesia Bagian Timur Di Semarang (Doctoral dissertation, Undip).

Feist, J. \& Gregory J. Feist. 2008. Theories of Personality (Edisi Keenam). Yogyakarta: Pustaka Pelajar.

Hurlock, E.B. 1997. Psikologi Perkembangan Sepanjang Rentang Kehidupan.Alih Bahasa Istiwidayanti dan Soedjarwo.Edisi kelima.Jakarta : Erlangga.

Haber, A., \& Runyon, R. D. 1984. Psychology of Adjustment. Illinois: The Dorsey Press.

Irfan, M., \& Suprapti, V. 2014.Hubungan self-efficacy dengan penyesuaian diri terhadap perguruan tinggi pada mahasiswa baru Fakultas Psikologi Universitas Airlangga. Jurnal Psikologi Pendidikan dan Perkembangan, 3(3), 172-178.

Kato, T. 2005. Adat Minangkabau dan Merantau dalam Perspektif Sejarah.Jakarta: Balai Pustaka

Lazarus. 1961. Adjustment Personality. New York. London: McGrow Hill Book Company.

Mahendrani, W., \& Rahayu, E. 2014).Hubungan antara Selfefficacy dengan Penyesuaian Diri pada Siswa Akselerasi. PSIKODIMENSIA, 1 $3(2)$.
Lent, R. W., Brown, S. D., \& Gore Jr, P. A. 1997.Discriminant and predictive validity of academic self-concept, academic selfefficacy, and mathematicsspecific self-efficacy. Journal of Counseling Psychology,44(3), 307.

Marsh, H. W., Smith, I. D., Barnes, J. 1985.Multidimensional SelfConcepts: Relation With Sex and Academic Achievement. Journal of EducationalPsychology, 77, 5564.

Putwain, D., Sander, P., \& Larkin, D. 2013.Academic self-efficacy in study-relatedemotions and academic success.British Journal of EducationalPsychology, 83, 633-650.

Partanto, P.A., Barry, M.D. 1994. Kamus Ilmiah Populer. Surabaya: Arloka.

Pietsch, J., Walker, R., Champman, E. 2003. The Relationship Among Self Concept, Self Efficacy, and Performance in Mathematics During Secondary School. Journal of Educational Psychology, 95, 589-603.

Rozali, Y. A. 2015. Hubungan efikasi diri akademik dan dukungan sosial orangtua dengan penyesuaian diri akademik pada mahasiswa UEU Jakarta. Jurnal Psikologi Esa Unggul, 13(02).
Runyon, R.P.\& Haber, A. 1984.Psychology of adjustment.Illinois : The Dorsey Press.

Santrock.(2002). Life span development.Dallas : Brown and Benchmark Inc. 
Sim, H.S., \& Weon, H. M. (2015).Relationships BetweenSelf Efficacy, Stress, Depression, and Adjustment of College Students.Indian Journal of Science and Technology.

Shaffer,\& Kipp. 2014. Developmental Psychology Childhood and Adolescence. Belmont: Wadsworth Cengage Learning

Sharma, B. 2012.Adjustment and Emotional Maturity Among First Year College Students. Pakistan Journal of Social and Clinical Psychology Vol. 9 No 3, 32-37.

Schneiders, A.A. 1964. Personal Adjustment and Mental Health. New York : Holt, Reinhart \& Winston Inc.

Shell, D.F., Murphy, C.C., Bruning, R. H. 1989.Self Efficacy and Outcome Expectancy Mechanism in Reading and Writing Achievement.Journal of Educational Psychology, 81, 91100.

Sawrey, J. M. dan Telford, C. W. 1968.Psychology of Adjustment (2nd Edition).Boston: Allyn and Bacon

Vembriarto. 1993. Sosiologi Pendidikan. Jakarta: Gramedia. 